\title{
APRESENTAÇÃO
}

\section{CURRÍCULO: criação e (re)insurgência}

\author{
Rafael Gonçalves' \\ Rosanne Evangelista Dias ${ }^{2}$
}

Somos convidados no primeiro número de 2020 da Revista Espaço do Currículo à leitura e provocação ao contarmos com uma seção temática e sessão de artigos livres, de fluxo contínuo a pensar temas urgentes de nossa agenda educacional focalizada no campo curricular. Um ano que inicia com intensos acontecimentos nos mobilizando sobre a vida, a convivência social, a solidariedade em meio a pandemia do covid-19.

Este convite não se faz com cerimônia e formalidade, mas como uma importante convocação a pensar sobre o currículo na luta política pela sua significação como ato de criação e como movimento de (re)insurgência. Assim, o Dossiê Currículo: criação e (re) insurgência pretende visibilizar a agenda das pesquisas em currículo que nos desafiam a pensar outros modos de produzir conhecimento no campo do currículo, em nossas investigações que buscam provocar ações teórico-estratégicas para nos fazer pensar sobre mundos, saberes, sujeitos, políticas que se forjam em diferentes espaçostempos.

No campo das políticas de currículo a luta por hegemonia nos sentidos que se pretendem ver reconhecidos como legitimados são postos em disputa, a todo momento. A luta pela hegemonia nos insta a provocar novas discussões com novos protagonistas para a pensarmos epistemologias que nos permitem incluir questões que urgem na luta pelas pautas que insurgem em meio a contextos singulares nos quais estamos envolvidos.

Neste dossiê contamos com diferentes autores provocando com suas ideias o pensar e dialogar sobre novas perspectivas nas investigações do campo do currículo. Tivemos a grata resposta de contar com os textos de autora mexicana e venezuelana e de diferentes estados brasileiros representando assim quase todas as regiões brasileiras, norte (Acre, Amazonas e Pará) nordeste (Paraíba, Pernambuco e Rio Grande do Norte), sudeste (Minas Gerais, Rio de Janeiro e São Paulo) e sul (Paraná).

Abrimos o dossiê com artigo de Ana Laura Gallardo intitulado Interculturalidad como discurso emergente en las reformas curriculares de la educación básica mexicana. Nele a autora analisa a centralidade assumida pelo discurso da interculturalidade nas reformas curriculares no México no período de vinte e quatro anos (1993-2017). Em seu trabalho propõe analisar os discursos dos textos políticos do período relatado apoiada pela genealogia de Michel Foucault e a teoria do discurso de Ernesto Laclau tencionando problematizar a interculturalidade como dimensão epistêmica das reformas curriculares.

Em outro artigo de autora latino-americana, El currículo en espacios transmodernos: lo implícito, significativo y emergente de la educación patrimonial transcompleja, Milagros Elena Rodriguez nos convida a pensar a abordagem hermenêutica para pensar a Educación Patrimonial Transcompleja (EPT). Sua proposição para explorar a tríade: patrimônio cultural - identidade - cidadania tem como defesa o desenvolvimento curricular sustentado na ideia de rede abordando a complexidade e a dimensão

1 Professor Adjunto I da Universidade Federal do Acre. Docente do quadro permanente do Programa de PósGraduação em Educação (PPGE-UFAC), vinculado a linha "Políticas e Gestão Educacional". E-mail: rafamg02@gmail.com. Orcid: https://orcid.org/0000-0002-9038-1542.

${ }_{2}^{2}$ Professora Adjunta da Faculdade de Educação da Universidade do Estado do Rio de Janeiro (UERJ) e Permanente no Programa de Pós-Graduação em Educação (Proped/UERJ) na linha Currículo: sujeito, conhecimento e cultura. Email: rosanne_dias@uol.com.br.orcid: https://orcid.org/0000-0002-3706-7626. 
transdisciplinar do que vai denominar por itinerário cultural emergente, formando os cidadãos dispostos a atenderem as demandas da cultura e do seu patrimônio cultural.

Amazônia - são muitas e o artigo Currículo escolar e práticas escolares de professoras sobre os saberes culturais da amazônia bragantina, de Deyverson Luener de Oliveira Ferreira e Ana Paula Vieira e Souza se propõe a discutir uma delas: a amazônia bragantina em sua experiência com a docência e suas concepções sobre o currículo escolar, as práticas escolares e os saberes culturais. Os autores focalizam a comunidade da Vila-Que-Era para problematizar a partir das narrativas dos professores e líderes comunitários os conflitos entre os saberes culturais da comunidade e ações da Secretaria Municipal de Educação no desenvolvimento curricular.

O artigo Currículo intercultural: experiência de construção com o povo Huni Kuin, de Lucia de Fatima Melo e Valda Inês Fontenele Pessoa aborda a construção do currículo intermunicipal do Curso Técnico Integrado ao Ensino Médio em Magistério Intercultural Indígena em parceria com Laboratório Intercultural - LABINTER da UFAC. Sua discussão centra na produção curricular a partir da experiência dos povos indígenas e da decisão política do povo Huni Kuin em meio as negociações e tensões que a caracterizam.

O Pibid como política de currículo para a formação de professores é o tema do artigo Currículo em postagens virtuais: o PIBID e os borramentos do lugar de formação de autoria de Claudia Tomé e Maria Santos. As autoras discutem como a docência é significada no movimento escola, universidade e mídias sociais: Whatsapp Messenger e Facebook. Nesses movimentos a produção curricular busca novos sentidos para a formação e a qualidade do ensino. No terreno da significação a docência é movimento constante de significação descentrando da instituição de verdades.

Wenderson Oliveira e Isabel Sabino apresentam uma fecunda discussão com seu artigo Currículos, Cotidiano(S) e Interseccionalidade: por um currículo-(r)existência. Defendem o cotidiano como espaçotempo privilegiado para a produção dos currículos escolares assumindo a interseccionalidade como abordagem teórico-metodológica central. Os autores nos convidam pensar como a interseccionalidade e as micropolíticas de existência podem ser fecundas na tentativa de constituir a justiça social nas escolas.

O artigo A educação em tempo integral no currículo do ensino médio integrado do IFMG, de Katia Regina de Sá e Marcos Garcia Neira nos apresentam o debate sobre as possíveis relações entre a educação profissional de nível médio e a educação em tempo integral (ETI) nas políticas de currículo do Instituto Federal de Educação, Ciência e Tecnologia de Minas Gerais (IFMG). Argumentam em defesa da seleção e organização dos saberes curriculares com a finalidade de atender ao direito dos estudos à formação plena, os autores destacam interessantes contribuições para a ETI no IFMG que estejam atentas às especificidades das juventudes e outros tempos da vida problematizando a jornada escolar ampliada.

No artigo Sentidos de professor nas políticas de formação continuada para a alfabetização, de Marize Peixoto da Silva Figueiredo, propõe com aportes pós-fundacionais orientada pela Teoria do Discurso de Ernesto Laclau e Chantal Mouffe e por suas apropriações no campo do currículo por Lopes \& Macedo e Oliveira. Ao interpretar os sentidos de professor alfabetizador sedimentados no Programa Nacional de Alfabetização na Idade Certa (PNAIC) e suas orientações para as políticas de formação de professores para desestabilizar os sentidos hegemônicos que intentam forjar o perfil do professor alfabetizador.

No último artigo do dossiê apresentamos o texto Resistir aos conhecimentos cristalizados para produzir outramentos no currículo, de Danilo Araujo e Anderson Ferrari, orientados pela perspectiva póscrítica os autores tencionam explorar a dinâmica do currículo do grupo LGBTQI+ Resistência pela democracia, organizado no Facebook. Os autores provocam-nos a pensar como o currículo resistência atua para que os sujeitos possam problematizar o outro de si mesmo por meio da insistência de questionamentos.

Na demanda contínua contamos neste número com oito artigos que muito se aproximam, na maior parte deles, das discussões promovidas pelo Dossiê. 
O primeiro deles, de autoria de Aline Renata dos Santos e Janssen Felipe da Silva, Políticas educacionais de livros didáticos no Brasil e na Colômbia: um olhar dos Estudos Pós-Coloniais aborda, sob o enfoque Pós-Colonial, a produção e distribuição de Livros Didáticos nos territórios campesinos do Brasil e da Colômbia. O artigo nos aponta para as aproximações entre Brasil e Colombia na produção e distribuição dos Livros Didáticos considerando os aspectos históricos, sociais e culturais.

No segundo artigo, O jogo no currículo uma estratégia etnomatemática de ação pedagógica, Filomena Maria Cordeiro Moita e Leandro Mario Lucas focalizam as potencialidades dos jogos como recursos que contribuem nas práticas educativas pautadas na Etnomatemática. Para a discussão, os autores exploram experiências acumuladas em sala de aula para dialogar com os pressupostos da Etnomatemática.

Os movimentos migratórios têm sido registrados em sua intensidade e complexidade no mundo e no Brasil podemos ver movimentos importantes que nos indagam sobre o acesso aos direitos básicos, como a educação escolarizada. No artigo de Giovani Giroto, Ercília Maria Angeli Teixeira de Paula, com abordagem dos estudos culturais, intitulado Imigrantes e refugiados no Brasil: uma análise acerca da escolarização, currículo e inclusão somos instados a refletir sobre essa questão a partir de uma pesquisa bibliográfica, quase um estado da arte, com a finalidade mapear o acesso de imigrantes e refugiados desde a educação básica ao ensino superior no Brasil.

O artigo A Base Nacional Comum Curricular e o uso das tecnologias na educação matemática: discursos da reforma curricular de autoria de Matheus dos Santos Souza e Marcelo de Oliveira Dias propõe discutir sobre as conexões entre a BNCC e as Tecnologias Digitais - TD no ensino de Matemática. Orientado pelos estudos pós-estruturais de Foucault e Deleuze, o artigo analisou movimentos de resistência no processo de produção da BNCC e os vínculos negociados entre formação para o trabalho e Tecnologias Digitais.

A questão ambiental assume centralidade no artigo Discursos ambientais no leste metropolitano fluminense: uma análise de documentos curriculares de Ana Paula de Sousa da Silva Melila e Maria Cristina Ferreira dos Santos. Quais as finalidades de ensino e as concepções de ambiente, presentes nos documentos curriculares? Para responder a essas questões, as autoras identificam que a disciplina Ciências nos PCN, no Currículo Mínimo do Rio de Janeiro e nas propostas curriculares municipais acabam explorando mais esse tema apontando pouco os currículos para questões de caráter socioambiental.

O que vem a ser o conceito de emancipação nos domínios da produção do conhecimento e da prática pedagógica? É a pergunta que pretende ser respondida pelo artigo de Elisandra de Souza Peres, José Carlos Bernardino Morgado, Prática pedagógica, currículo e emancipação: significados e perspectivas que apresenta os resultados de um estudo exploratório. Nele os autores apresentam o resultado de uma pesquisa exploratória em que entrevistaram professores das Universidades do Minho e do Porto (Portugal) para compreensão de como o conceito vem sendo mobilizado nas instituições envolvidas tanto no plano teórico como no plano das práticas curriculares desenvolvidas nas instituições educativa.

Joseane da Silva Miller Rodrigues e Noemi Boer, Fernanda Marquezan nos apresentam o artigo Marcos regulatórios e as implicações na organização do currículo para educação infantil brasileira nos apresentam, por meio de uma revisão bibliográfica, o processo de normatização da Educação Infantil no Brasil e suas repercussões no plano curricular. No estudo apresentado as autoras também buscam a discussão sobre a organização curricular da Educação Infantil consultando como importantes fontes autores e documentos normativos da área.

O Bullying é a temática do artigo que nos apresenta Catarina Carneiro Gonçalves e Fernando Cézar Bezerra de Andrade intitulado Currículos da formação docente inicial e o despreparo para manejar o bullying na escola para problematizar, com base na Análise da Enunciação proposta por Bardin, como vem sendo formado os professores nos cursos de Pedagogia para lidar com a violência escolar, destacadamente, o Bullying. 